\title{
Epidemiological, clinical and evolutionary aspects of tuberculosis among elderly patients of a university hospital in Belém, Pará
}

Emanuele Cordeiro Chaves, ${ }^{1,2}$

Irna Carla do Rosário Souza Carneiro? Maria Izabel Penha de Oliveira Santos ${ }^{2,3}$

Nathália de Araújo Sarges ${ }^{2,3}$

Eula Oliveira Santos das Neves ${ }^{2}$

\section{Abstract}

Objective: To evaluate the epidemiological, clinical and evolutionary aspects of tuberculosis in elderly patients of a university hospital in Belém, Pará. Method: A cross-sectional study was conducted in a university hospital, where 82 records of cases of tuberculosis in elderly patients were analyzed. The data was analyzed by applying the G-test, assuming a level of $\alpha=0.05(5 \%)$ and a value of $p=0.05$. Results: Most of the elderly patients were male (64.6\%), aged 60-69 years, especially among men (64.2\%). Most were new cases of tuberculosis $(95.1 \%$ ), with a pulmonary clinical form $(75.6 \%)$, associated diseases $(69.5 \%)$ and a length of stay exceeding 21 days. Fever (67.1\%), dyspnea (64.6\%), weight loss $(61.0 \%)$, productive cough $(59.8 \%)$, chest pain $(51.2 \%)$ were the main signs and symptoms. Regarding treatment, there was a high percentage of adverse reactions $(50 \%)$, predominantly gastrointestinal events (70.7\%). Most patients were cured $(59.8 \%)$, but mortality from tuberculosis was considered high (15.9\%). In terms of the exposure variables and outcome, there was a statistically significant difference for the age group ( $p=0.017)$, length of stay $(p=0.000)$ and adverse reactions $(p=0.018)$ only. Conclusion: The clinical presentation and therapeutic management of tuberculosis among the elderly has characteristics peculiar to this group, making it important to strengthen strategies that facilitate early identification of suspected cases of TB among elderly persons in the community, which should take place mainly through the primary care system.

\footnotetext{
Universidade Federal do Pará, Núcleo de Medicina Tropical, Programa de pós-graduação em Doenças Tropicais. Belém, PA, Brasil.

2 Universidade do Estado do Pará, Grupo de Ensino, Pesquisa e Extensão sobre o Envelhecimento e Saúde do Idoso da Amazônia (GESIAMA). Belém, PA, Brasil.

3 Universidade do Estado do Pará, Programa de Mestrado Associado UEPA/UFAM. Belém, PA, Brasil.
}

Keywords: Elderly.

Tuberculosis. Diagnosis.

Drug Therapy Combination. 


\section{INTRODUCTION}

Tuberculosis is an infectious disease transmitted predominantly through the air. The evolution of the disease is chronic, affecting mainly the lungs, and its etiological agent is the Mycobacterium tuberculosis (MT) bacterial species. According to the World Health Organization (WHO), it is estimated that a third of the world's population is infected with MT, with more than eight million new cases and three million deaths from the disease every year ${ }^{1}$.

Brazil reported 68,000 new cases of tuberculosis in 2014. This high incidence puts the country in $16^{\text {th }}$ position among the 22 countries with a high disease burden, in terms of number of cases. There were around 4,600 deaths caused by tuberculosis in 2013, and it remains the third highest cause of death due to infectious diseases and the number one cause of death among infectious diseases in AIDS patients ${ }^{2}$.

In Brazil, demographic and subsequent epidemiological transition has occurred in an atypical form, characterized by the reemergence or constant presence of infectious and parasitic diseases, as well as by the higher prevalence of non-transmissible chronic diseases and disorders ${ }^{3}$.

In this context, the loss of cellular immune reactivity to MT often occurs among the elderly, making them more vulnerable to both exogenous infection and the reactivation of foci containing latent bacilli4.

In addition, the symptoms of the disease are difficult to measure among the elderly due to the frequent concomitance of respiratory, cardiovascular and systemic diseases, which present a similar clinical picture, combined with the difficulty elderly persons experience in reporting complaints due to memory deficit, confused states, senility and problems with verbalization, which results in delayed diagnosis ${ }^{5}$.

The treatment of tuberculosis demonstrates the same efficacy among elderly and young people, and with the correct and timely use of medication, a cure can be expected in both groups. However, there are peculiarities inherent to the elderly, such as memory deficit, polypharmacy and the frequent occurrences of adverse effects in this population group. It is therefore essential that treatment is supervised to enable the early detection of adverse effects, guarantee the intake of medication and consequently increase indicators of cures ${ }^{6}$.

The objective of the present study was to evaluate the epidemiological, clinical and evolutionary aspects of tuberculosis among the elderly.

\section{METHOD}

An epidemiological cross-sectional study was performed. The research was carried out in a university hospital in Belém, Pará, Brazil, using records of cases of tuberculosis diagnosed from 2009 to 2013. As a complementary form of obtaining data, the database of the Sistema Nacional de Agravos de Notificação (the National System of Notificable Diseases) (SINAN) and the Secretaria de Estado de Saúde Pública (the State Public Health Department) (SESPA) were consulted.

The following inclusion criteria were adopted: aged 60 years or older, represent a new case or recurrence or re-admission after the cessation of treatment for pulmonary or extrapulmonary tuberculosis, and having started treatment at the institution where the survey was performed. Incomplete medical records were defined as exclusion criteria, as was the closure of the case due to a change in diagnosis.

A total of 2,458 cases of tuberculosis were reported at the institution where the study was carried out during the study period, of which 148 involved hospitalized elderly persons. When the inclusion and exclusion criteria mentioned above were applied, a final sample of 82 elderly people was defined and had their medical records analyzed.

Data collection was performed by the nurse who coordinated the study and a previously trained and supervised nursing student, through the application of a research instrument on the medical records 
of the patients diagnosed with tuberculosis, and a search for the evolution of the cases in SINAN.

The data collection instrument was based on the terminology used by SINAN and was previously tested on 15 medical records (three for each year of the study). The variables studied were socio-demographic data (age, gender, level of schooling and municipality of origin), epidemiological data (hospital stay, type of entry, clinical form of disease, associated diseases and use of medications), clinical signs and symptoms (adverse reaction to anti-tuberculosis drugs, postdischarge follow-up and outcome).

The data was analyzed through descriptive and analytical statistics, using the G-test, adopting a level of $\alpha=0.05(5 \%)$ and a $\mathrm{p} \leq 0.05$ value, in order to identify the statistical significance in the differences between the categories of variables studied.

The study plan was approved by the Ethics Research Committee of the Núcleo de Medicina Tropical (Tropical Medicine Center)/Universidade Federal do Pará (Pará Federal University), under record $n^{\circ}$ 1.081.347. As the study used secondary data, the use of a Free and Informed Consent Form
(FICF) was not required, however, the use of the data was authorized by the institution.

\section{RESULTS}

There was a predominance of male patients among the 82 medical records evaluated. The mean age was 69.8 ( \pm 7 ) years, with a concentration in the age range of 60-69 years in both genders, most notably among men. Most elderly persons had a complete or incomplete elementary education and came from Belém, Pará or its metropolitan area (Table 1).

Most of the patients were new tuberculosis cases, were not institutionalized and had pulmonary tuberculosis. There was a predominance of elderly individuals who reported having at least one associated disorder at the time of admission, with smoking, alcoholism, diabetes mellitus and hypertension most notable. It was found that the majority of the elderly persons used between one and four medications. The mean hospitalization time was 21.9 ( \pm 15.9 ) days, with the period over 21 days predominating (Table 2).

Table 1. Sociodemographic data of elderly persons with tuberculosis, by gender (n=82). Belém, Pará, 2009-2013.

\begin{tabular}{|c|c|c|c|}
\hline Variables & $\begin{array}{l}\text { Male } \\
\mathrm{n}(\%)\end{array}$ & $\begin{array}{l}\text { Female } \\
\mathrm{n}(\%)\end{array}$ & $p$ \\
\hline Gender & $53(64.6)$ & $29(35.4)$ & \\
\hline Age range & & & 0.009 \\
\hline 60-69 & $34(64.2)$ & $13(44.8)$ & \\
\hline $70-79$ & $16(30.2)$ & $13(44.8)$ & \\
\hline $80-89$ & $3(5.7)$ & $0(0.0)$ & \\
\hline$\geq 90$ & $0(0.0)$ & $3(10.3)$ & \\
\hline Level of schooling & & & 0.074 \\
\hline Illiterate & $4(7.5)$ & $6(20.7)$ & \\
\hline Elementary complete/incomplete & $37(69.8)$ & $19(65.5)$ & \\
\hline High school complete/incomplete & $5(9.4)$ & $0(0.0)$ & \\
\hline Not recorded & $7(13.2)$ & $4(13.8)$ & \\
\hline Municipality of origin & & & 0.528 \\
\hline Belém/metropolitan area & $38(71.7)$ & $23(79.3)$ & \\
\hline Countryside of state & $14(26.4)$ & $6(20.7)$ & \\
\hline Other state & $1(1.9)$ & $0(0.0)$ & \\
\hline
\end{tabular}

Medical records of patients; $p$ value $\leq 0.05$; $G$ test. 
Table 2. Epidemiological data of elderly persons with tuberculosis (n=82). Belém, Pará, 2009-2013

\begin{tabular}{ll}
\hline Variables & $\mathrm{n}(\%)$ \\
\hline Type of entry & \\
New case & $78(95.1)$ \\
Relapse & $3(3.7)$ \\
Reentry after abandonment & $1(1.2)$ \\
\hline Institutionalized* & \\
Yes & $4(4.9)$ \\
No & $78(95.1)$
\end{tabular}

Clinical form

$\begin{array}{lc}\text { Pulmonary } & 62(75.6) \\ \text { Pleural } & 10(12.2) \\ \text { Ganglionic } & 1(1.2) \\ \text { Bone } & 1(1.2) \\ \text { Peritoneal } & 1(1.2) \\ \text { Combination of forms } * * & 7(8.5)\end{array}$

Associated disorders***

Yes $57(69.5)$

No 25 (30.5)

Disorders identifiedo

Smoking 28 (49.1)

$\begin{array}{ll}\text { Alcoholism } & 21(36.8)\end{array}$

Diabetes Mellitus 21 (36.8)

Arterial hypertension $\quad 20$ (35.1)

AIDS 2 (3.5)

Number of medications $x$, o

$\begin{array}{ll}\geq 5 & 22(26.8) \\ 1 \text { to } 4 & 57(69.5) \\ \text { None } & 3(3.7)\end{array}$

Time of hospitalization (days)

$\leq 7 \quad 15(18.3)$

8-15 $24(29.3)$

$16-21 \quad 5(6.1)$

$\geq 21 \quad 38(46.3)$

Medical records of patients; *Patients in prison, asylum, orphanage and psychiatric hospital; **Pulmonary and pleural (85.21\%), pulmonary and ganglionic $(14.29 \%)$; $* * *$ Reported, at time of admission, at least one associated disorder; $\not$ Considering only those patients who presented at least one disease; a a Medications during hospitalization.

The main signs and symptoms presented by the elderly persons with tuberculosis were fever, dyspnea, weight loss, productive coughing and chest pain (Table 3).

Half of the elderly persons presented an adverse reaction to the specific drug regimen, the most common of which were gastrointestinal manifestations. Few, however, needed to suspend or replace their treatment regimen. A minority of the elderly persons with tuberculosis underwent Directly Observed Treatment (DOT) following discharge or sputum smear microscopy for treatment control. Regarding the outcome, more than half of the cases resulted in a cure, however, the high number of deaths specifically caused by tuberculosis is also noteworthy (Table 4). 
Table 3. Clinical data of elderly persons with tuberculosis (n=82), Belém, Pará, 2009-2013.

\begin{tabular}{ll}
\hline Variables & $\mathrm{n}(\%)$ \\
\hline Signs and symptoms & $55(67.1)$ \\
Fever & $53(64.6)$ \\
Dyspnea & $50(61.0)$ \\
Weight Loss & $49(59.8)$ \\
Productive cough & $42(51.2)$ \\
Chest pain & $24(29.3)$ \\
Fatigue & $20(24.4)$ \\
Dry cough & $19(23.2)$ \\
Hyporexia & $18(22.0)$ \\
Hemoptoic sputum & $8(9.8)$ \\
Sweating &
\end{tabular}

Medical records of patients.

Table 4. Evolutionary data of the elderly with tuberculosis (n=82). Belém, Pará, 2009-2013.

\begin{tabular}{|c|c|}
\hline Variables & $\mathrm{n}(\%)$ \\
\hline \multicolumn{2}{|l|}{ Adverse reaction } \\
\hline Yes & $41(50.0)$ \\
\hline No & $41(50.0)$ \\
\hline \multicolumn{2}{|l|}{ Type of adverse reaction* } \\
\hline Gastrointestinal manifestations & $29(70.7)$ \\
\hline Neurological manifestations $* *$ & $14(34.1)$ \\
\hline Rheumatological manifestations $* * *$ & $11(26.8)$ \\
\hline Hepatotoxicity & $10(24.4)$ \\
\hline Dermatological manifestations & $9(22.0)$ \\
\hline Cardiovascular manifestations & $3(7.3)$ \\
\hline Nephrotoxicity & $1(2.4)$ \\
\hline \multicolumn{2}{|l|}{ Management of reaction } \\
\hline Suspension of treatment & $13(31.7)$ \\
\hline Replacement of therapeutic regimen & $2(4.9)$ \\
\hline \multicolumn{2}{|l|}{ Post-discharge follow-up } \\
\hline Directly Observed Treatment & $23(31.9)$ \\
\hline Sputum smear microscopy & $20(50.0)$ \\
\hline \multicolumn{2}{|l|}{ Final outcome } \\
\hline Cure & $49(59.8)$ \\
\hline Abandonment & $2(2.4)$ \\
\hline Death due to tuberculosis & $13(15.9)$ \\
\hline Death due to other causes & $6(7.3)$ \\
\hline Transfer to another state & $1(1.2)$ \\
\hline Multidrug-resistant tuberculosis & $1(1.2)$ \\
\hline No information & $10(12.2)$ \\
\hline
\end{tabular}

Medical records of patients; ${ }^{*}$ Considering only patients who exhibited an adverse reaction; ${ }^{* *}$ Peripheral neuropathy, headache, insomnia, psychosis, convulsive crisis, disorientation, dizziness, paresthesia of the lower limbs and drowsiness; *** Joint pain, low back pain and neck pain; 0 Hypotension and tachycardia. 
Table 5. Exposure variables by outcome (n=62). Belém, Pará, 2009-2013.

\begin{tabular}{|c|c|c|c|}
\hline Variables & $\begin{array}{l}\text { Cure } \\
\mathrm{n}(\%)\end{array}$ & $\begin{array}{l}\text { Death by tuberculosis } \\
\mathrm{n}(\%)\end{array}$ & $* p$ \\
\hline Age range & & & 0.017 \\
\hline $60-69$ & $33(67.3)$ & $4(30.8)$ & \\
\hline $70-79$ & $14(28.6)$ & $6(46.2)$ & \\
\hline $80-89$ & $2(4.1)$ & $1(7.7)$ & \\
\hline$\geq 90$ & $0(0.0)$ & $2(15.4)$ & \\
\hline Gender & & & 0.343 \\
\hline Male & $31(63.3)$ & $10(76.9)$ & \\
\hline Female & $18(36.7)$ & $3(23.1)$ & \\
\hline Time of hospitalization (days) & & & 0.000 \\
\hline$\leq 7$ & $4(8.2)$ & $7(53.8)$ & \\
\hline $8-15$ & $18(36.7)$ & $0(0.0)$ & \\
\hline $16-21$ & $3(6.1)$ & $1(7.7)$ & \\
\hline$>21$ & $24(49.0)$ & $5(38.5)$ & \\
\hline Associated disorders & & & 0.789 \\
\hline Yes & $32(65.3)$ & $9(69.2)$ & \\
\hline No & $17(34.7)$ & $4(30.8)$ & \\
\hline Adverse reaction & & & 0.018 \\
\hline Yes & $20(40.8)$ & $10(76.9)$ & \\
\hline No & $29(59.2)$ & $3(23.1)$ & \\
\hline Directly observed treatment post-discharge & & & 0.123 \\
\hline Yes & $18(36.7)$ & $2(15.4)$ & \\
\hline No & $31(63.3)$ & $11(84.6)$ & \\
\hline
\end{tabular}

Medical records of patients; ${ }^{*} p$ value $\leq 0.05$; $\mathrm{G}$ test.

In terms of the relationship between the exposure variables and the outcome, it was found that cure occurred more frequently among elderly persons in the 60-69 year age group, whereas death was more frequent in patients in the 70-79 year age range. This relationship was statistically significance. There was no statistical significance between the outcome and the variables gender, associated disorders and DOT. Patients who died due to tuberculosis had a shorter hospital stay ( $\leq 7$ days) and an adverse reaction to the specific tuberculosis treatment regimen (Table 5).

\section{DISCUSSION}

The majority of the elderly persons were male, which can be explained by the fact that male subjects are less careful about their health, and are therefore more likely to require hospitalization ${ }^{7}$.
In addition, tuberculosis historically affects men more than women, across all age groups. According to Ministry of Health data, $66.8 \%$ of tuberculosis cases registered in 2014 involved men, a percentage very close to that found in this study ${ }^{2}$.

These gender differences may be due to the greater presence of men in the labor market, their lower utilization of health services, and a higher prevalence of HIV infection, alcoholism and drug abuse, conditions that make them more vulnerable to infection and tuberculosis ${ }^{8}$.

In terms of age group, there was a predominance of elderly persons aged between 60-69 years, and the mean age was $69.8( \pm 7)$ years. This is close to the findings of a study carried out in South Korea which had an average patient age of 72 years ${ }^{9}$. 
In terms of the level of schooling, the majority of men and women had a complete or incomplete elementary education. In the case of tuberculosis, schooling is an extremely important factor, as illiteracy and a low level of education are more likely to be related to the abandonment of treatment, due to the more limited understanding and access of such individuals to information about the disease ${ }^{10}$.

Regarding the municipality of origin, the majority of elderly persons of both genders came from the metropolitan area of Belém, Pará. This was expected, considering that the largest number of cases of tuberculosis in the state are concentrated in this region. Tuberculosis, in general, is concentrated in urban centers, as its distribution influenced by factors such as land use extension, disordered population growth and the concentration of people in the peripheries ${ }^{11}$.

The vast majority of the elderly patients were new cases, that is, they had never been treated for tuberculosis or had received such treatment for a period of up to 30 days. Previous treatment history is of fundamental importance, considering that retreatment of tuberculosis is one of the main risk factors associated with the development of drug resistance ${ }^{12}$. In the present study, $95.1 \%$ of the elderly persons were new cases, which may explain the reduced percentage of drug resistance identified, which was only $1.2 \%$.

Pulmonary tuberculosis was the predominant clinical form in $75.6 \%$ of the elderly persons studied, proportional to that reported in the literature for this age group ${ }^{6}$. Such a result was expected, given that the lung is the entry point for MT and that from there the bacillus can spread by contiguity (causing the pleural form), or by lymphatic (lymph node) or hematogenic (pleural, ganglionic and other extrapulmonary forms) routes, especially in cases of immunosuppression ${ }^{13}$, as in the case of the present study, in which extrapulmonary forms or a combination of forms were responsible for $24.4 \%$ of cases, notably pleural tuberculosis (12.2\%).

Regarding the presence of disorders associated with tuberculosis, $69.5 \%$ of elderly persons reported having at least one such condition. Among the disorders identified were smoking, alcoholism, diabetes mellitus, hypertension and AIDS.
Smoking, specifically, has been found to more prevalent in patients with tuberculosis than among the general population, and may be associated with a higher rate of disease recurrence and with a longer sputum smear conversion period. The inhalation of smoke can alter the defense mechanisms of the respiratory system, thus reducing the concentration of blood oxygen, contributing to the increased severity of necrotizing lesions and slowing the cicatrization process, and so generate more extensive pulmonary sequelae ${ }^{14}$.

The problems related to alcohol consumption in the elderly are common yet little known, and as a result are described by some authors as an "invisible epidemic." Excessive alcohol consumption increases the chance of the development of adverse effects and hepatotoxicity, as well as being a factor that predisposes a treatment regimen to unfavorable results ${ }^{15}$.

The presence of Diabetes Mellitus predisposes an individual to tuberculosis infection, since hyperglycemia and insulin reduction interfere with immune response, acting directly on the cellular function of macrophages and lymphocytes and altering chemotactic function, phagocytosis and antigen presentation. While the clinical presentation of tuberculosis in diabetics is similar to that traditionally presented by the disease, the control of diabetes is often difficult, and the radiological image may appear atypical, making diagnosis difficult ${ }^{16}$.

In relation to the number of drugs used by the elderly, it was found that the majority used between one and four medications. However, a significant percentage $(26.8 \%)$ used five or more drugs. According to the criteria of the Centro Ibero-Americano para a Terceira Idade (the IberoAmerican Center for the Elderly) this number represents polypharmacy ${ }^{17}$. If the four drugs that make up the tuberculosis treatment regimen are taken into account, it can be considered that $96.7 \%$ of the elderly persons are employing polypharmacy.

The majority of the elderly persons were hospitalized for an average of around three weeks, with about one third of patients hospitalized for two weeks, which may reflect a slower response to antituberculostatic therapy in these patients, or the presence of underlying diseases requiring 
compensation, such as diabetes mellitus, making hospitalization more prolonged. In addition, a long hospital stay is associated with the occurrence of hospital infection, which makes the elderly person more vulnerable and fragile due to their lower physiological capacity to overcome such conditions ${ }^{18}$.

Regarding clinical characteristics, the clinical manifestation most reported by the elderly was fever (67.1\%). However, a study in Rio de Janeiro, comparing clinical manifestations of tuberculosis among the elderly and non- elderly, found that the presence of fever was more common among the latter $(69.3 \%)$ than the former $(55.4 \%)$ group 5 .

Dyspnoea was identified in $64.6 \%$ of the elderly, which represents a considerably higher percentage than the findings of another study which involved both this age group and the general population ${ }^{5}$. This result indicates that most of the elderly persons in the present study were hospitalized at a late stage of the disease and in a highly aggravated state.

Weight loss was reported by $61 \%$ of patients. Findings in literature on weight loss in elderly persons with tuberculosis are controversial. A study carried out in Rio de Janeiro, for example, identified this clinical manifestation in $79.1 \%$ of the elderly ${ }^{5}$. This can be associated with the duration and the extension of the disease, as these are proportional to weight loss ${ }^{1}$.

The presence of productive cough (59.8\%) was more prevalent than dry cough $(24.3 \%)$, which confirms the late diagnosis of the elderly, considering that coughing, which becomes aggravated over time, can evolve into coughing with expectoration. However, it should also be considered that the high percentage of elderly persons with a history of smoking may mask the number of coughs resulting from tuberculosis.

Adverse reactions affected $50 \%$ of the elderly, as identified in a similar study carried out with pulmonary tuberculosis at the Instituto de Doenças do Tórax (Institute of Chest Diseases) of the Universidade Federal do Rio de Janeiro (Rio de Janeiro Federal University), where adverse reactions occurred in $45.9 \%$ of elderly persons ${ }^{19}$.
A systematic review that investigated risk factors for the development of adverse reactions to the treatment of tuberculosis in the period 1965 to 2012 identified that being aged over 60 years was one such risk factor, due to the elderly having a slower metabolism, caused by reduced enzyme activity, decreased hepatic clearance, and reduced availability of essential endogenous cofactors ${ }^{20}$.

Gastrointestinal manifestations were observed in $70.7 \%$ of the elderly. Such manifestations are the most frequent adverse reactions to tuberculosis treatment and may be caused by rifampicin, isoniazid, pyrazinamide and ethambutol ${ }^{20,21}$. In a study of tuberculosis patients, gastrointestinal effects were found to be related to elderly individuals, revealing that the treatment toxicity associated with the use of other continuous medications and the presence of comorbidities increased the frequency of adverse events in this age group ${ }^{21}$.

Neurological manifestations (peripheral neuropathy, headache, insomnia, psychosis, convulsive crisis, disorientation, dizziness, paresthesia of the lower limbs and somnolence) occurred in $34.1 \%$ of elderly persons who suffered an adverse effect. These manifestations are commonly related to the intake of isoniazid, with peripheral neuropathy the most frequent complaint, requiring the daily oral supplementation of pyridoxine $(50 \mathrm{mg})$, especially in elderly individuals, aimed at minimizing polyneuropathy ${ }^{22}$.

Rheumatologic manifestations (joint pain, low back pain and neck pain) occurred in $26.8 \%$ of elderly patients who presented adverse reactions. Joint pains are considered minor side effects and, when unrelated to hyperuricemia, are often associated with the use of pyrazinamide, and less with the use of isoniazid, as pyrazinoic acid (the main metabolite of pyrazinamide) acts to inhibit the tubular secretion of uric acid, causing an increase in serum concentration, and consequently joint pain ${ }^{20}$.

Rheumatologic manifestations resulting from adverse reactions should be carefully analyzed, however, so as not to confuse them with the predisposing conditions for this symptom, such as underlying diseases (arthritis, arthrosis and osteoporosis), lack of movement due to bed rest and advancing age. 
Hepatotoxicity corresponded to $24.4 \%$ of adverse reactions. Literature supports this finding, as in a systematic review carried out on the subject, an age lower than 60-65 years was found to be a protection factor for the development of druginduced hepatotoxicity ${ }^{20}$.

According to the Ministry of Health classification, hepatotoxicity is a major adverse effect and may be caused by pyrazinamide, or more frequently, by isoniazid and rifampicin ${ }^{21}$. The incidence of hepatotoxicity induced by isoniazid or rifampicin in isolation is low $(0.6 \%$ and almost zero, respectively), but increases by $2.7 \%$ when both drugs are combined ${ }^{23}$. The high levels of alcoholism in this study may be one of the factors related to the development of hepatotoxicity in the elderly.

Temporary withdrawal from treatment is recommended when hepatic transaminase levels increase five times or more above normal, until the resolution of symptoms or the return to baseline liver enzyme levels, with the subsequent separate reintroduction of the drugs over a period of three days to one week, seeking to identify which drug was responsible for the adverse effect, and carry out its substitution ${ }^{6}$.

Despite the high percentage of elderly patients who exhibited adverse reactions, only $31.7 \%$ needed to discontinue treatment, and $4.9 \%$ had their treatment replaced by a special regimen, a result very similar to a study of the general population carried out in São Paulo, in which the modification of therapy due to adverse effects occurred in $3.7 \%$ of cases $^{23}$.

The need to discontinue treatment was not higher in the present study because the majority of adverse reactions were less severe (gastrointestinal). In these cases, interventions such as counseling, the rescheduling of the administering of medication, and the use of symptomatic medication are sufficient for the control of signals and symptons ${ }^{21,23}$.

The early detection of adverse reactions is of fundamental importance, and relatives and caregivers should be advised about the appearance of such reactions, especially in cases where the elderly person has difficulty with verbalization, the perception of symptoms or cognitive deficit.
Although post-discharge DOT was performed in $31.9 \%$ of the elderly, it should be applied to every such individual, as the memory deficit, polypharmacy and frequent occurrences of adverse effects among this population group require that treatment is supervised, as a form of early detection of adverse effects, the guarantee of medication intake and the subsequent increase of cure indicators ${ }^{6}$.

However, it should be considered that the supervision of the treatment of the elderly may have been delegated to the patient's family members or caregiver by the health professional, and in these cases, such individuals should be advised of the correct dose and times for drug administration, drug interaction, and adverse effects.

Sputum smear microscopy for the control of treatment was performed in only $50 \%$ of patients initially treated with bacilli. The monthly sputum smear is indispensable in the second, fourth and sixth months, being an important criterion for monitoring the effectiveness of treatment and consequent confirmation of a cure, the need to extend the treatment for another three months, or the suspicion of non-tuberculosis mycobacterial infection or drug resistance ${ }^{21}$.

Regarding treatment outcome, the majority of patients were cured (59.8\%), and the abandonment rate was $2.4 \%$. These results were considerably lower than the national average for the general population, which was $11.1 \%$ in $2013^{2}$.

However, the high percentage of deaths due to tuberculosis $(15.9 \%)$ should also be highlighted. This finding was similar to those of a study conducted in Rio de Janeiro, in which the proportion of deaths was much higher in the elderly group than among the non-elderly ${ }^{19}$.

When the age range was related to the outcomes, it was found that the highest proportion of cured cases were in the age group between 60-69 years, while those who died were in the age group of 7079 years. This difference was statistically significant. A prospective cohort study of the period 19952004 showed that older patients with tuberculosis have a higher mortality rate, but this difference is minimized if diagnosed early and properly treated ${ }^{24}$. 
Regarding the relationship between hospitalization time and outcome, a statistically significant difference was found, with most of the patients who died from tuberculosis hospitalized for a period of up to seven days, indicating that these patients were in an aggravated state when hospitalized, as can be verified by the high

Adverse reactions were more frequent in patients who died as a result of the disease than in those who were cured, and the difference between the two groups was statistically significant. This situation is possibly due to a more severe clinical condition, indicating the need for immediate intervention in these cases.

The main limitations of the study are that data collection was retrospective and documentary, which generated information bias, with the loss of some records. The characteristics of the association between comorbidities and illnesses and the phenomenon of polypharmacy represent a challenge for the management of tuberculosis in the elderly. Due to the reduced sample size, the results cannot be

\section{REFERENCES}

1. Melo FF, Affune JB, Hijjar MA, Gomes M, Rodrigues DSS, Klautau GB, et al. Tuberculose. In: Focaccia R, Diament D, Ferreira MS, Siciliano RF. Veronesi: Tratado de infectologia. $4^{\mathrm{a}}$ ed. São Paulo: Editora Atheneu; 2009. p.1263-300.

2. Ministério da Saúde. Secretaria de Vigilância à Saúde,Programa Nacional de Controle da Tuberculose [Internet]. Brasília, DF: Ministério da Saúde; 2015 [acesso em 21 nov. 2015]. Disponível em: https://drive.google.com/file/d/0B0CE2wqdEaRWUJ0RWZPcG0zM00/view

3. Pereira RA, Alves-Souza RA, Vale JS. O processo de transição epidemiológica: uma revisão de literatura. Rev Científ Fac Educ Meio Amb. 2015;6(1):99-108.

4. Hussein MT, Youssef LM, Abusedera MA. Pattern of pulmonary tuberculosis in elderly patients in Sohag Governorate: hospital based study. Egypt J Chest Dis Tuberc. 2013;62(2):269-74.

generalized and should be interpreted with caution. Case control or large cohort studies are therefore needed to better understand the peculiarities of tuberculosis in this population.

\section{CONCLUSION}

The majority of the elderly patients were new cases, who suffered from pulmonary tuberculosis, were carrying bacilli, had illnesses and disorders associated with the disease, used polypharmacy, and were at an advanced stage of the disease. It is worth noting that a considerable percentage suffered adverse reactions, mainly gastrointestinal and neurological manifestations, however, discharge following a cure occurred in the majority of cases, despite the significant death rate due to tuberculosis.

Considering the above, it is important to strengthen strategies that allow the early identification of elderly persons suspected of tuberculosis in the community, which should occur mainly in the Primary Care system.
5. Cantalice Filho JP, Sant'anna CC, Bóia MN. Aspectos clínicos da tuberculose pulmonar em hospital universitário do Rio de Janeiro, RJ, Brasil. J Bras Pneumol . 2007;33(6):699-706.

6. Chaimowicz F, Miranda SS. Tuberculose pulmonar. In: Freitas EV, Py L, Nery AL, Cançado FAXC, Gorzoni ML, Doll J. Tratado de geriatria e gerontologia. $3^{\mathrm{a}}$ ed. Rio de Janeiro: Guanabara Koogan; 2011. p. 644-56.

7. Storti LB, Fabrício-Whebe SCC, Kusumota 1, Rodrigues RAP, Marques S. Fragilidade de idosos internados na clínica médica da unidade de emergência de um hospital geral terciário. Texto \& Contexto Enferm. 2013;22(2):452-9.

8. Oliveira Júnior HS, Mendes DHC, Almeida RB. Prevalência de casos de tuberculose durante anos de 2002 a 2012, no município de Palmas-Paraná, Brasil. Rev Saúde Pública. 2015;8(1):43-57. 
9. Kwon YS, Chi SY, Oh IJ, Kim KS, Kim YI, Lim SC, et al. Clinical characteristics and treatment outcomes of tuberculosis in the elderly: a case control study. BMC Infect Dis. 2013;13(121):1-7.

10. Furlan MCR, Oliveira SP, Marcon SS. Fatores associados ao abandono do tratamento de tuberculose no estado do Paraná. Acta Paul Enferm. 2012;25(1):108-14.

11. Queiroga RPF, Sá LD, Nogueira JA, Lima ERV, Silva ACO, Pinheiro PGOD, et al. Distribuição espacial da tuberculose e a relação com condições de vida na área urbana do município de Campina Grande - 2004 a 2007. Rev Bras Epidemiol. 2012;15(1):222-32.

12. Zhao Y, Xu S, Wang L, Chin DP, Wang S, Jiang G, et al. National server of drug-resistant tuberculosis in China. N Eng J Med. 2012;366(1):2161-70.

13. Bethlem EP. Manifestações clínicas da tuberculose pleural, ganglionar, geniturinária e do sistema nervoso central. Pulmão RJ. 2012;21(1):19-22.

14. Pinto Neto LFS, Vieira NFR, Cott FS, Oliveira FMAl. Prevalência da tuberculose em pacientes infectados pelo vírus da imunodeficiência humana. Rev Soc Bras Clin Med. 2013;11(2):118-22.

15. Silva PF, Moura GS, Caldas AJM. Fatores associados ao abandono do tratamento da tuberculose pulmonar no Maranhão, Brasil, no período de 2001 a 2010. Cad Saúde Pública. 2014;30(8):1745-54.

16. Seiscento M. Tuberculose em situações especiais: HIV, diabetes mellitus e insuficiência renal. Pulmão RJ. 2012;21(1):23-6.
17. Silva R, Schmidt OF, Silva S. Polifarmácia em geriatria. Rev AMRIGS. 2012;56(2):164-74.

18. Costa FM, Nunes RS, Santos JAD, Carneiro JA. Fatores associados à ocorrência de infecção hospitalar em idosos: uma revisão integrativa. Rev Norte Min Enferm. 2015;4(1):70-86.

19. Cantalice Filho JP, Bóia MN, Sant’anna CC. Análise do tratamento da tuberculose pulmonar em idosos de um hospital universitário do Rio de Janeiro, RJ, Brasil. J Bras Pneumol. 2007;33(6):691-8.

20. Resende LSO, Santos-Neto ETS. Fatores associados às reações adversas a medicamentos antituberculose. J Bras Pneumol. 2015;41(1):77-89.

21. Ministério da Saúde. Secretaria de Vigilância em Saúde, Departamento de Vigilância Epidemiológica. Manual de recomendações para o controle da tuberculose. Brasília, DF: Ministério da Saúde; 2011.

22. Maciel ELN, Guidoni LM, Favero JL, Hadad DJ, Monilo LP, Jonhson JL, et al. Efeitos adversos causados pelo novo esquema de tratamento da tuberculose preconizado pelo Ministério da Saúde do Brasil. J Bras Pneumol. 2010;36(2):232-8.

23. Vieira DEO, Gomes M. Efeitos adversos no tratamento da tuberculose: experiência em serviço ambulatorial de um hospital-escola na cidade de São Paulo. J Bras Pneumol. 2008;34(12):1049-55.

24. Salvadó M, García-Vidal C, Vásquez P, Riera M, Rodríguez-Carballeira M, Martínez-Lacasa J, et al. Mortality of tuberculosis in very old people. J Am Geriatra Soc. 2010;58(1):18-22. 